\title{
Removal of surfactant from industrial wastewaters by coagulation flocculation process
}

\author{
${ }^{1 *}$ M. A. Aboulhassan, ${ }^{1}$ S. Souabi, ${ }^{2}$ A. Yaacoubi and ${ }^{3}$ M.Baudu \\ ${ }^{1}$ Laboratoire de Génie de l'Eau et de l'Environnement, Faculté des Sciences et Techniques, BP 146 Mohammedia, \\ Maroc \\ ${ }^{2}$ Laboratoire de Chimie Organique Appliquée, Faculté des Sciences Semlalia, Marrakech, Maroc \\ ${ }^{3}$ Laboratoire de l'Eau et l'Environnement, Faculté des sciences de Limoges, France \\ Received 25 March 2006; revised 10 May 2006; accepted 7 September 2006; available online 1 October 2006
}

\begin{abstract}
Surfactants are among the most widely disseminated xenobiotics that contribute significantly to the pollution profile of sewage and wastewaters of all kinds. Among the currently employed chemical unit processes in the treatment of wastewaters, coagulation-flocculation has received considerable attention for yielding high pollutant removal efficiency. Jar-test experiments are employed in order to determine the optimum conditions for the removal of surfactants, COD and turbidity in terms of effective dosage, and $\mathrm{pH}$ control. Treatment with $\mathrm{FeCl}_{3}$ proved to be effective in a $\mathrm{pH}$ range between 7 and 9 . The process is very effective in the reduction of surfactants and COD, the removals are 99 and $88 \%$ respectively, and increased $\mathrm{BOD}_{5} / \mathrm{COD}$ index from 0.17 to 0.41 . In addition to precipitation coagulation process, adsorptive micellar flocculation mechanism seems contribute to the removal of surfactants and organic matters from this rejection.
\end{abstract}

Key words: Iron chloride, industrial wastewaters, surfactants, coagulation flocculation

\section{INTRODUCTION}

Surfactants are in widespread use throughout the world. The use of surfactant is gradually increased day by day; the world surfactant production was 1.7, 1.8 and 9.3 million tons in the years 1984, 1987 and 1995, respectively. A wide range of these products are actually synthesized and used in several domains such as textiles, fibbers, food, paints, polymers, cosmetics, pharmaceuticals, microelectronic, mining, oil recovery, pulp-paper industries, etc. Anionic surfactants are the major class of surfactants used in detergent formulations and represent about $59 \%$ of surfactants used in 1989 (Mathis, 1992). Surfactants are among the most widely disseminated xenobiotics that may enter waste streams and the aquatic environment (Sigoillot and Nguyen, 1992; Margesin and Schinner, 1998; Eichhorn, et al., 2001, 2002). They are harmful to human beings, fishes and vegetation; and are responsible to cause foams in rivers and effluent treatment plants and to reduce the quality of water. Surfactants cause short term as well as long-term changes in ecosystem. Due to all these reasons, many environmental and public

\footnotetext{
*Corresponding author, Email: a.aboulhassan@gmail.com
} Tel.: +2126 7517 817; Fax: +2122 3315353 health regulatory authorities have fixed stringent limits for anionic detergent as standard $0.5 \mathrm{mg} / \mathrm{L}$ for drinking water and relaxable up to $1.0 \mathrm{mg} / \mathrm{L}$ for other purposes (Rao, 1995). Surfactants removal operations involve processes such as chemical and electrochemical oxidation (Lissens, et al., 2003; Mozia, et al., 2005), membrane technology (Sirieix-Plénet, et al., 2003; Kowalska, et al., 2004; Fernández , et al., 2005), chemical precipitation (Shiau, et al., 1994; Talens-Alesson, et al., 2002), photocatalytic degradation (Rao and Dube, 1996; Ohtaki, et al., 2000; Zhang, et al., 2003), adsorption (Ogita, et al., 2000; Lin, et al., 2002; Adak, et al., 2005) and various biological methods (Matthew and Malcolm, 2000; Dhouib, et al., 2003; Chen, et al., 2005). Each has its merits and limitation in application. Surfactants containing wastewaters treatment by biological processes such as activated sludge is problematic due to the low kinetics of degradation and to foam production (Dhouib, et al., 2003). Among the currently employed chemical unit processes in wastewater treatment, coagulation-flocculation has received considerable attention for yielding high pollutant removal efficiency. This process can be 
directly applied to wastewaters without being affected by the toxicity in the wastewater and could constitute a simple, selective and economically acceptable alternative. The objectives of this study are the examination of coagulation precipitation process efficiency for the treatment of industrial wastewaters with high surfactants content, especially in terms of organic matter and surfactants removals. More specifically, the aim is the determination of the most appropriate iron chloride dose, the examination of $\mathrm{pH}$ effects on removal capacity and the identification of optimum experimental conditions for the efficient application of this process.

\section{MATERIALSAND METHODS}

Sampling procedures

Samples of effluent are collected from outfall of a microelectronic factory situated in an industrial park of the Casablanca city, Morocco. The generated effluent is discharged into the sea without any treatment. Sampling of the wastewater is carried out according to standard methods for the examination of wastewater.

\section{Chemical coagulation and analysis}

Laboratory scale evaluation of chemical coagulation and flocculation is performed using a four-place jar test apparatus. The experimental process consisted of three subsequent stages: initial rapid mixing stage at $160 \mathrm{rpm}$ took place for $5 \mathrm{~min}$, followed by a slow mixing stage for $20 \mathrm{~min}$ at $30 \mathrm{rpm}$, and the final settling step lasted for another $1 \mathrm{~h}$. Four equal volume polyethylene beakers are used to examine the four different dosages of coagulant or initial $\mathrm{pH}$ values in each run. Sample bottles are thoroughly shaken, for resuspension of possibly settling solids and the appropriate volume of sample is transferred to the corresponding jar test beakers. First, the optimum $\mathrm{pH}$ for the function of iron is determined. A known volume of prepared ferric chloride solution is added to a jar containing $1 \mathrm{~L}$ of wastewaters at different $\mathrm{pH}$ values adjusted with $\mathrm{H}_{2}(\mathrm{SO})_{4}$ and $\mathrm{NaOH}$. To investigate the optimum coagulant dose, the $\mathrm{pH}$ value of the wastewater is maintained at an optimum $\mathrm{pH}$ as determined above; and varying doses of iron are then added. After 60 min settling, the supernatant is withdrawn for analyses. To asses the efficacy of iron on wastewater treatment, the following are determined: turbidity, chemical oxygen demand(COD) and surfactants. Turbidity: the turbidity is determined by turbidity meter (HI 93703 Microprocessor turbidity meter).

Chemical oxygen demand: COD and other physicochemical parameters (BOD, NTK, Pt....) for wastewater characterisation measurement are performed according to Standard Methods (AFNOR, 1999). Surfactants: detergent compounds are determined using solvent extraction-spectrophotometric with Ethyl Violet method (Motomizu, et al., 1982).

\section{RESULTS}

Fluctuation range of the measured values for COD, BOD, NTK, surfactants, total phosphorus....etc, are given in Table 1. The wastewater is characterised by substantial organic matter and high surfactants contents. The company uses a liquid anionic surfactant on the manufacturing process, it is a mixture of ammonium nonylphenol ether sulphate (60\%), ethanol (15\%), water (25\%), dioxane $(<0.1 \%)$ and ethylene oxide $(<0.0015 \%)$. In fact, the wastewaters did not meet the proposed Moroccan effluent standards. In order to meet these trade-related demands and to respect acceptable environmental standards, it is necessary to subject effluents to an appropriate treatment. BOD/ COD ratios indicate that a biological treatment seems to be not suitable (Metcalf and Eddy Inc, 1985; AlMomani, et al., 2002), and then a physicochemical process is required.

Table 1: Microelectronic plant wastewater characteristics

\begin{tabular}{lclc}
\hline Parameters & Fluctuation range & Average & Moroccan guide level \\
\hline $\mathrm{pH}$ & $7.00-7.60$ & $7.3 \pm 0.25$ & $6.5-8.5$ \\
Conductivity (ms/cm) & $0.60-0.75$ & $0.66 \pm 0.06$ & 2.7 \\
Turbidity(NTU) & $15.91-34.50$ & $24.35 \pm 7.75$ & - \\
Sulphate (mg/L) & $45.6-58.2$ & $52.2 \pm 5.89$ & - \\
Pt (mg/L) & $1.27-1.42$ & $1.335 \pm 0.06$ & 10 \\
NTK(mg/L) & $65.38-72.58$ & $69.24 \pm 3.19$ & 30 \\
$\mathrm{COD}(\mathrm{mg} / \mathrm{L})$ & $5253.62-6333.44$ & $5846.76 \pm 508$ & 500 \\
$\mathrm{BOD}(\mathrm{mg} / \mathrm{L})$ & $951.21-1051.45$ & $998.16 \pm 41.28$ & 100 \\
Surfactants $(\mathrm{mg} / \mathrm{L})$ & $915.32-956.51$ & $935.45 \pm 17.31$ & 3 \\
BOD $/ \mathrm{COD}$ & $0.16-0.18$ & $0.16 \pm 0.008$ & - \\
\hline
\end{tabular}


Removal of surfactant from...

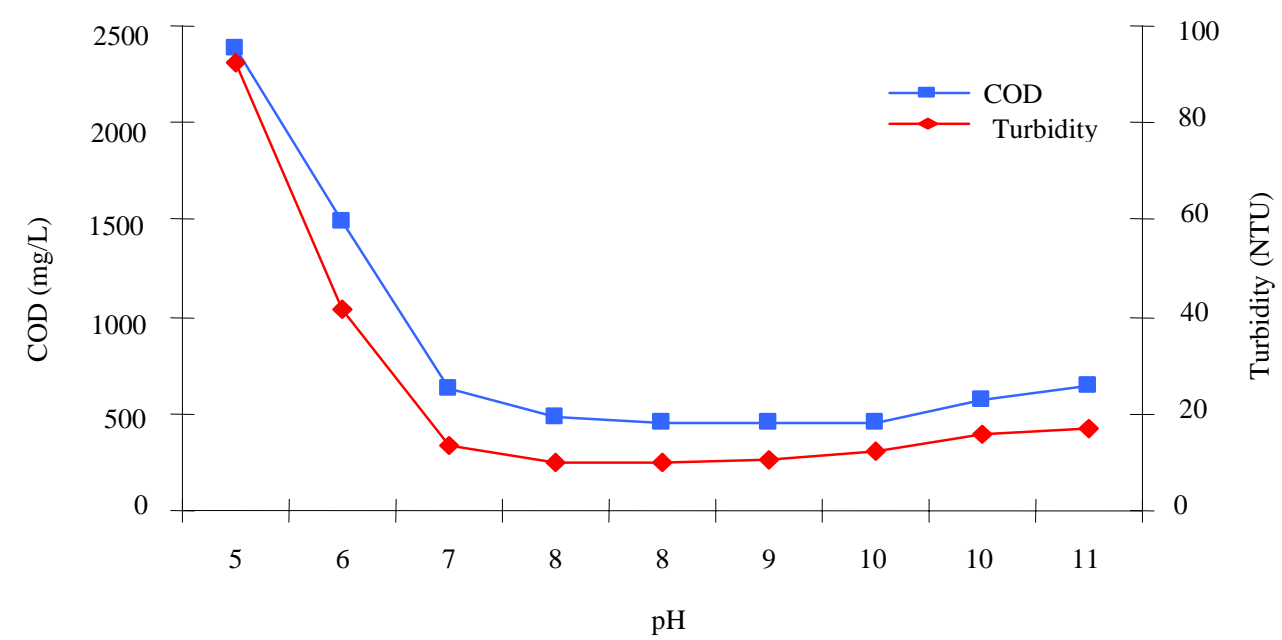

Fig. 1: Effect of coagulation $\mathrm{pH}$ on $\mathrm{FeCl}_{3}$ efficiency

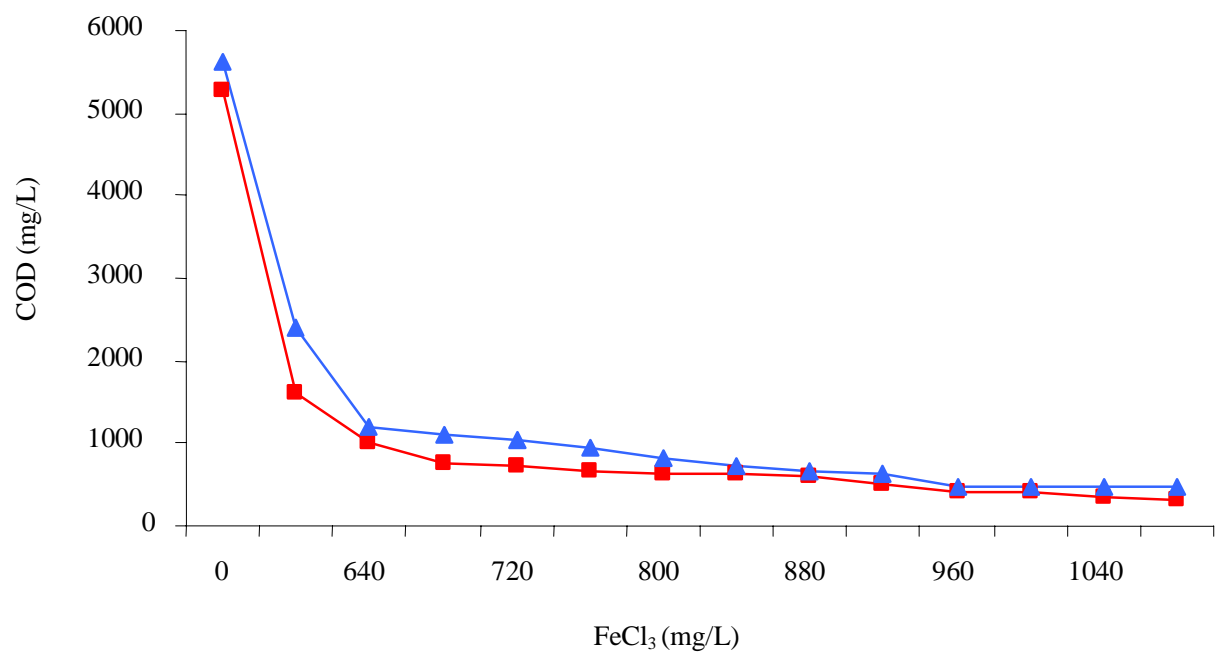

Fig. 2: Effect of $\mathrm{FeCl}_{3}$ on $\mathrm{COD}$ reduction

Table 2: Characteristics of raw and treated wastewaters

\begin{tabular}{llc}
\hline Parameters & Raw wastewaters & Coagulated wastewaters \\
\hline $\mathrm{pH}$ & $7.3 \pm 0.25$ & $2.4 \pm 0.25$ \\
$\mathrm{BOD}_{5} / \mathrm{COD}$ & $0.16 \pm 0.008$ & $0.408 \pm 0.01$ \\
Surfactants (mg/L) & $935.45 \pm 17.31$ & $4.6 \pm 1.25$ \\
\hline
\end{tabular}

Coagulation flocculation process is examined for the treatment of the effluent. Numerous jar tests are carried out in order to establish a practical understanding of the coagulation performance for this application. Initially the tests are carried out to determine the optimum $\mathrm{pH}$ for the function of iron. A fixed dose of iron is added to the effluent wastewater and the $\mathrm{pH}$ of the mixture is then adjusted with sodium hydroxide and sulphuric acid. The effects of $\mathrm{pH}$ on turbidity and COD removal from jar tests for coagulation of wastewater using ferric chloride are shown in Fig. 1. It can be seen that turbidity and COD removals are most effective at a pH range between 7 and 9. The rate of turbidity and COD removal decreased if the $\mathrm{pH}$ was lower than 7 or higher than 9. Experiments were carried out to determine the optimum dose of iron. The coagulation flocculation of wastewater is investigated using iron doses of $600-1100 \mathrm{mg} / \mathrm{L}$ at coagulation $\mathrm{pH}=8$. Coagulated wastewater samples are tested for residual COD and surfactants. The removal rate is shown to increase with the $\mathrm{FeCl}_{3}$ dosage (Figs. 2 and 3).

\section{DISCUSSION AND CONCLUSION}

Figs. 2 and 3 indicate that a minimum dosage of $\mathrm{FeCl}_{3}$ of $900 \mathrm{mg} / \mathrm{L}$ is required on the reduction of COD and surfactants load from the wastewater by coagulation 
M. A. Aboulhassan, et al.

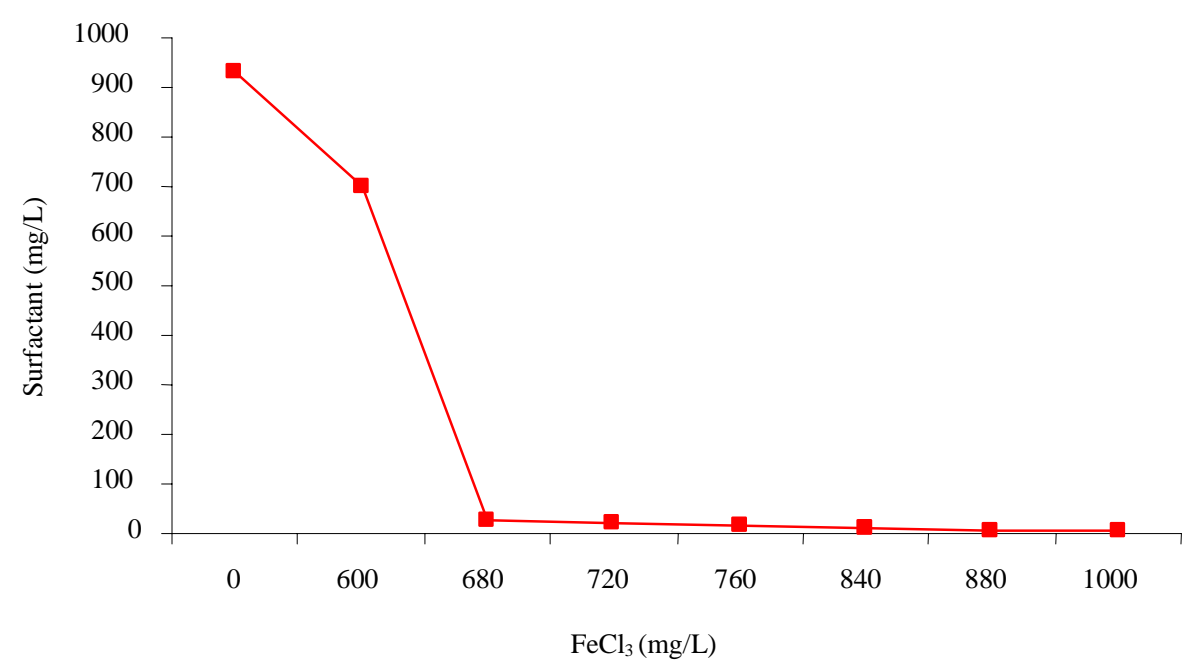

Fig. 3: Effect of $\mathrm{FeCl}_{3}$ on surfactant removals

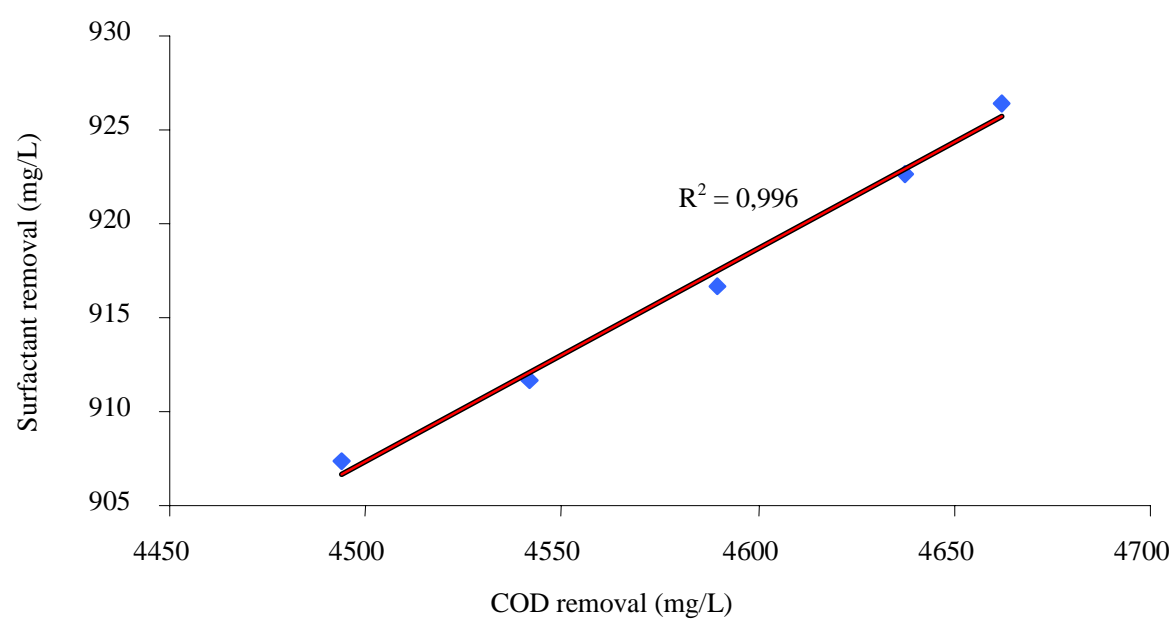

Fig. 4: Correlation between COD and surfactants removals

to an acceptable level. At this optimum dosage, the COD removal reach $88 \%$ and it is reduced to approximately $400 \mathrm{mg} / \mathrm{L}$, and then the treated wastewaters respect the Moroccan acceptable environmental standard in terms of COD $(500 \mathrm{mg} / \mathrm{L})$. The process is also effective in the reduction of surfactants which reached $99 \%$. However, residual surfactants in treated wastewaters (Table 2) are slightly above than this recommended by Moroccan legislation ( $3 \mathrm{mg} / \mathrm{L}$ ). Then, a further treatment is necessary to allow the surfactants guide level. The effect of iron on pollutants reduction shows that there is a comparable evolution between COD and surfactants removals. Fig. 4 shows positive correlation between COD and surfactants removals, $\mathrm{R}^{2}=0.99$. It indicates that there exists similar mechanism for the removal of surfactants and organic matters. Thus the conditions for precipitation coagulation of the surfactant correspond with the conditions for precipitation coagulation of the other substances. Talens-Alesson, et al. (2002) report that $\mathrm{Fe}^{3+}$ can be used as an alternative to $\mathrm{Al}^{3+}$ in adsorptive micellar flocculation (AMF). They concluded that the $\mathrm{pH}$ range of $\mathrm{Fe}^{3+}$ solutions resulting from flocculation of anionic surfactant sodium dodecyl sulphate solutions with $\mathrm{Fe}^{3+}$ is $1.8-2.5$. On the basis of the results obtained on surfactants and COD removals and on the $\mathrm{pH}$ of coagulated wastewaters at $\mathrm{pH}=2.4$ (Table 2), it seem that, in addition to precipitation coagulation process, AMF mechanism contributes to the removal of surfactants and organic matters from this rejection. The cations $\mathrm{Fe}^{3+}$ binds itself to a micelle, causing two simultaneous effects: it suppresses repulsion between 
micelles flocculating them and effectively removing micellar surfactant from solution in the form of an aggregate, and it binds organic compounds to the flocs (Porras et Talens, 1999, 2000; Talens-Alesson, 2001). It can be concluded that, in addition to precipitation coagulation process, adsorptive micellar flocculation mechanism seems contribute to the removal of surfactants and organic matters from this rejection. Many authors use the ratio BOD/COD as biodegradability index (Chamarro, et al., 2001; Scott et Ollis, 1995). Table 2 shows that $\mathrm{BOD}_{5} / \mathrm{COD}$ ratio for initial and treated wastewaters changed from 0.16 to 0.41 . It can be seen that the process leads to noticeable improvement in the biodegradability index for the microelectronic plant wastewaters. This improvement in biodegradability is due to reduction in the proportion of COD not amenable to biological mineralization. Wastewater can be considered readily biodegradable if it has a $\mathrm{BOD}_{5} / \mathrm{COD}$ ratio between 0.4 and 0.8 (Metcalf and Eddy, 1985; Al-Momani, et al., 2002). This limit is reached for the microelectronic plant wastewaters, which indicates that a biological treatment can be applied as a further treatment to enhance the pollutants removal and to more reducing of surfactants contents to allow the guide level.

\section{REFERENCES}

Adak, A.,Bandyopadhyay, M. and Pal, A., (2005). Removal of anionic surfactant from wastewater by alumina: a case study. Colloid. Surface., 254, 165-171.

AFNOR (Association Française de Normalisation), la qualité de l'eau, 1999.

Al-Momani, F., Touraud, E., Degorce-Dumas, J. R., Roussy, J., Thomas, O., (2002). Biodegradability enhancement of textile dyes and textile wastewater by UV photolysis. J. Photochem. Photo., Chem., 153, 191-197.

Chamarro, E., Marco, A., Esplugas, S., (2001). Use of Fenton reagent to improve organic chemical biodegradability. Water Res., 35, 1047-1051.

Chen, H. J., Tseng, D. H. and Huang, S. L., (2005). Biodegradation of octylphenol polyethoxylate surfactant Triton X-100 by selected microorganisms. Biores. Technol., 96, 1483-1491.

Dhouib, A., Hamad, N., Hassaïri, I. and Sayadi, S., (2003). Degradation of anionic surfactants by Citrobacter braakii. Proc. Biochem., 38, 1245-1250.

Eichhorn, P., Flavier, M. E., Paje, M. L., Knepper, T. P., (2001). Occurrence and fate of linear and branched alkylbenzene sulfonates and their metabolites in surface waters in Philippines. Sci. Total Environ., 269, 75-85.

Eichhorn, P., Rodrigues, S. V., Baumann, W. and Knepper, T. P., (2002). Incomplete degradation of linear alkylbenzene sulfonate surfactants in Brazilian surface waters and pursuit of their polar metabolites in drinking waters. Sci. Total Environ., 284, 123-134.
Fernández, E., Benito, J. M., Pazos, C. and Coca, J., (2005). Ceramic membrane ultrafiltration of anionic and nonionic surfactant solutions. J. Mem. Sci., 246, 1-6.

Kowalska, I., Kabsch-Korbutowicz, M., Majewska-Nowak, K., Winnicki, T., (2004). Separation of anionic surfactants on ultrafiltration membranes. Desalination, 162, 33-40.

Lin, Y., Smith, T. W. and Alexandridis, P., (2002). Adsorption of a polymeric siloxane surfactant on carbon black particles dispersed in mixtures of water with polar organic solvents. J. Coll. Interf. Sci., 255, 1-9.

Lissens, G., Pieters, J., Verhaege, M., Pinoy, L. and Verstraete, W., (2003). Electrochemical degradation of surfactants by intermediates of water discharge at carbon-based electrodes. Electrochemi. Acta, 48, 1655-1663.

Margesin, R. and Schinner, F., (1998). Low-temperature bioremediation of a wastewater contaminated with anionic surfactants and fuel oil. Appl. Microbiol. Biotechnol. 49, 482-486.

Mathis, A., (1992). Les produits tensioactifs. Bulletin de l’Union des Physiciens. 86, 1487-1501.

Matthew, J. S. and Malcolm, N. J., (2000). The biodegradation of surfactants in the environment. Biochimica and Biophysica Acta (BBA). Biomem., 1508, 235-251.

Metcalf and Eddy Inc., (1985). Wastewater Engineering: Treatment, Disposal and Reuse, 3rd ed., McGraw-Hill, New York, USA.

Motomizu, S., Fujiwara, S., Fujiwara, A. and Toel, K., (1982). Solvent extraction-spectrophotometric determination of detergent compounds in solution with Ethyl Violet. Anal. Chem. 54, 392-397.

Mozia, S., Tomaszewska, M. and Morawski, A.W., (2005). Decomposition of nonionic surfactant in a labyrinth flow photoreactor with immobilized TiO2 bed. Appl. Catal. Environ., 59, 155-160.

Ogita, M., Nagai, Y., Mehta, M. A., and Fujinami, T., (2000). Application of the adsorption effect of optical fibres for the determination of critical micelle concentration, Sensor. Actuator., 64, 147-151.

Ohtaki, M., Sato, H., Fujii, H. and Eguchi, K., (2000). Intramolecularly selective decomposition of surfactant molecules on photocatalytic oxidative degradation over TiO2 photocatalyst. J. Molecul. Catalysis., 155, 121-129.

Porras, M. and Talens, F. I., (1999). Removal of 2,4-D from aqueous solutions by micellar flocculation. Sep. Sci. Technol., 34, 2679-2684.

Porras, M., Talens, F. I., (2000). Removal of 2,4-D from aqueous solutions by micellar flocculation with $\alpha$-olefinsulphonates. Sep. Sci. Technol. 35, 1973-1978.

Rao, C. S., (1995). Environmental pollution control engineering. Wiley Eastern Ltd., 301.

Rao, N. N. and Dube, S., (1996). Photocatalytic degradation of mixed surfactants and some commercial soap/detergent products using suspended $\mathrm{TiO}_{2}$. Catal. J. Molecul. Catal., 104, 197-199.

Scott, J. P. and Ollis, D. F., (1995). Integration of chemical and biological oxidation processes for water treatment: review and recommendations. Environ. Prog., 14, 88-103.

Shiau, B., Harwell, J. H. and Scamehorn, J. F., (1994). Precipitation of mixtures of anionic and cationic surfactants: III. Effect of added nonionic surfactant. J. Colloid Interf. Sci., 167, 332-345. 
Sigoillot, J. C. and Nguyen, M. H., (1992). Complete oxidation of linear alkyl-benzene sulfonate by bacterial communities selected from coastal seawater. Appl. Environ. Microbiol., 58, 1308-1312.

Sirieix-Plénet, J., Turmine, M. and Letellier, P., (2003). Membrane electrodes sensitive to doubly charged surfactants. Application to a cationic gemini surfactant. Talanta, 60, 1071-1078.

Talens-Alesson, F. I., (2001). Binding of pesticide 2,4-D to SDS and AOS micellar flocculates. Colloid. Surfac., 180, 199-203.
Talens-Alesson, F. I., Hall, S. T., Hankins, N. P., Azzopardi, B. J., (2002). Flocculation of SDS micelles with $\mathrm{Fe}^{3+}$. Colloid. Surface., 204, 85-91.

Zhang, T., Oyama, T., Horikoshi, S., Zhao, J., Serpone, N. and Hidaka, H., (2003). Photocatalytic decomposition of the sodium dodecylbenzene sulfonate surfactant in aqueous titania suspensions exposed to highly concentrated solar radiation and effects of additives. Appl. Environ., 42, 1324.

\section{AUTHOR(S) BIOSKETCHES}

Aboulhassan, M. A., is a doctor, Faculty of Sciences and Technologies, Hassan II Mohammedia University, Mohammedia, Morocco. Email: a.aboulhassan@gmail.com.

Souabi, S., is a professor, Faculty of Sciences and Technologies, Hassan II Mohammedia University, Mohammedia, Morocco. Email: s_souabi@yahoo.fr.

Yaacoubi, A., is a professor, Faculty of Sciences Semlalia, Cadi Ayyad University, Marrakech, Morocco.

Baudu, M., is a professor; Faculty of Sciences and Technologies, Limoges University,

Limoges, France. Email: baudu@unilim.fr

This article should be referenced as follows:

Aboulhassan, M. A., Souabi, S., Yaacoubi, A. and Baudu, M., (2006). Removal of surfactant from industrial wastewaters by coagulation flocculation process. Int. J. Environ. Sci. Tech., 3 (4), 327-332 